\title{
Ten Years of The Journal of Smoking Cessation
}

Renee Bittoun

Founding Editor
The advent and success of a new Journal seems to be dependent on its originality and a readership that needs and appreciates the content. It still is surprising to me personally that the Journal of Smoking Cessation (JoSC) has succeeded to such a degree since its inception 10 years ago. When I thought about a Journal for our group of the Australian Association of Smoking Cessation Professionals (AASCP), the publishers at Australian Academic Press asked whether there surely was such a journal already and that another might be redundant. When I assured them that there was no such Journal, we embarked upon an enterprise which now has great international interest and credibility. With a small startup grant from the Australian Government I was able to encourage and recruit old friends and colleagues from around the world who were all kind enough to give their names in good faith to an Editorial Board that remains the same today. Their good names and reputations greatly enhanced the credibility of the Journal and I cannot thank them enough for their faith in the Journal and its future. In particular thanks go to Michelle DiGiacomo for volunteering and continuing to volunteer an inordinate amount of time and energy supporting this endeavour.
The Journal, almost entirely dedicated to articles related to helping smokers quit or manage their smoking, has published articles that stand out as strategies for clinicians to adhere to. The Journal has published then novel treatments for the first time, such as Varenicline and papers on the use of $\mathrm{E}$ cigarettes for cessation. It was and remains the agenda of the Journal to publish evidence based strategies in the field of smoking cessation in order to raise the scientific level of interventions and eliminate the often used 'tip' based help that pervades the area of 'life-style' treatments carried out by unqualified and often unscrupulous 'practitioners'.

Since the acquisition of JoSC by Cambridge University Press we have seen the addition of the USA group ATTUD (Association for the Treatment of Tobacco Use and Dependence) and their tobacco treatment specialists who have incorporated the JoSC as their journal. This addition has strengthened the credibility of the JoSC and Tobacco Treatment Specialists around the world and we look forward to incorporating other groups from around the world to join in on this growing demand for evidencebased intervention helping prevent the scourge of tobacco use and dependence around the globe. 